\title{
Interaction between protein 4.1R and spectrin heterodimers
}

\author{
DAO-QIANG ZHANG, YUN-PENG WANG, WEN-HU WANG, XIU-MEI SUI, JUN-QIANG JIANG, \\ XIAO-MEI JIANG, ZU-SHAN XU and YAN-GUANG LIU
}

Weifang Medical College, Wendeng Central Hospital, Weihai, Shandong 264400, P.R. China

Received January 10, 2011; Accepted March 22, 2011

DOI: $10.3892 / \mathrm{mmr} .2011 .470$

\begin{abstract}
Defects or deficiencies in red cell membrane skeletal proteins often undermine the integrity and stability of the plasma membrane, and consequently cause hereditary hemolytic anemias. Genetic and biochemical studies have revealed a complicated picture of the organization of the membrane skeleton, within which $\alpha$-/ $\beta$-spectrin heterodimers form a protein lattice. By stabilizing the red cell membrane skeleton, the erythroid protein $4.1 \mathrm{R}$ greatly contributes to connecting and regulating the interaction among spectrins, actin filaments and integral proteins on the plasma membrane. In this study, we demonstrated the direct interaction between $4.1 \mathrm{R}$ and $\alpha-/ \beta$-spectrin. The results provide novel insights into the stoichiometry of $4.1 \mathrm{R}$ with spectrin, and demonstrate for the first time that the binding ratio of $4.1 \mathrm{R}$ to spectrin heterodimers is approximately 5 .
\end{abstract}

\section{Introduction}

The erythroid cytoskeleton is comprised of a number of proteins, which structurally support the cell membrane and also functionally regulate membrane trafficking and signaling transduction. Among these membrane skeletal proteins, the spectrin-ankyrin-4.1-adducin complex represents a striking system. Mutations or impairments in this complex lead to various diseases, in particular hereditary hemolytic anemias. In red blood cells (RBCs), the spectrin-ankyrin-4.1-adducin based membrane-cytoskeletal system plays a crucial role in stabilizing the lipid bilayer and endowing RBCs with the ability to endure the rigorous stresses encountered during circulation (1).

Regarding the structure of the membrane-cytoskeletal system within RBCs, spectrin and actin filaments form the backbone underneath the membrane macrocomplexes, and other proteins are connected to the backbone. Among them, the proteins $4.1 \mathrm{R}$ and adducin modulate the junction between spectrin and actin, and ankyrin links $\beta$-spectrin and connects the membrane macrocomplexes (2). Thus, spectrin filaments

Correspondence to: Dr Yan-Guang Liu, Weifang Medical College, Wendeng Central Hospital, Weihai, Shandong 264400, P.R. China E-mail: ken20012006@yahoo.com

Key words: protein 4.1R, spectrin, binding, red blood cells, membrane appear to be the determinant of the RBC membrane, while other proteins are also crucial for the integrity of membrane structure and functionality. For example, protein 4.1R acts as a multifunctional component and regulates the junctions of the membrane-skeletal network. Mutations or defects in 4.1R cause instability of the network and consequently the whole cell membrane $(3,4)$.

In this study, to better understand RBC membrane organization, we investigated the interaction between spectrin and protein 4.1R using a variety of biochemical strategies. Our data demonstrated that 4.1R protein binds and forms a stable complex with the spectrin heterodimers, and that the binding ratio of 4.1R to spectrin heterodimers is approximately 5 . These findings suggest that this interaction contributes to the stabilization of the membrane-cytoskeletal system within RBCs.

\section{Materials and methods}

Materials. Chemical reagents were purchased from Sigma. The expression vector pGex-6P, glutathione (GSH) sepharose beads, and a Sephacryl S-200 column were purchased from GE Healthcare. The antibody against the human protein 4.1R was obtained from Santa Cruz Biotechnology.

Extraction and purification of human $4.1 R$ protein. The human protein 4.1R was extracted and purified from human RBCs according to a previously described protocol $(5,6)$. The quality and identity of $4.1 \mathrm{R}$ protein were assessed by SDS-PAGE and Western blotting. The 4.1R protein was dialyzed against binding buffer $(120 \mathrm{mM} \mathrm{KCl}, 10 \mathrm{mM} \mathrm{N}$-2-hydroxyethylpiperazine-N'2-ethanesulfonic acid, $0.5 \mathrm{mM}$ ethyleneglycoltetraacetic acid and $0.5 \mathrm{mM}$ dithiothreitol, $\mathrm{pH}$ 7.5) (6).

Expression and purification of spectrins. Human cDNA for $\alpha-$ and $\beta$-spectrin was cloned into the expression vector pGex-6P. The recombinant plasmids were transferred into the $E$. coli BL21 cells. The recombinant proteins were isolated and purified according to the manufacturer's protocol. The GST tag was cleaved off from the $\alpha$-spectrin following the manufacturer's directions, while the GST tag was kept uncleaved with the $\beta$-spectrin. The purified proteins were dialyzed against the binding buffer.

Formation of minispectrin heterodimers. Equal amounts of $\alpha$ - and $\beta$-spectrins at molar concentrations were combined and allowed to form heterodimers overnight on ice. The mixed 
A

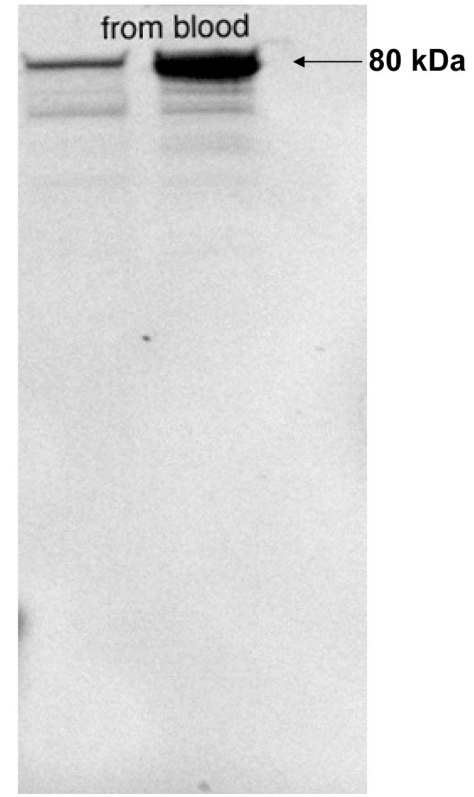

B

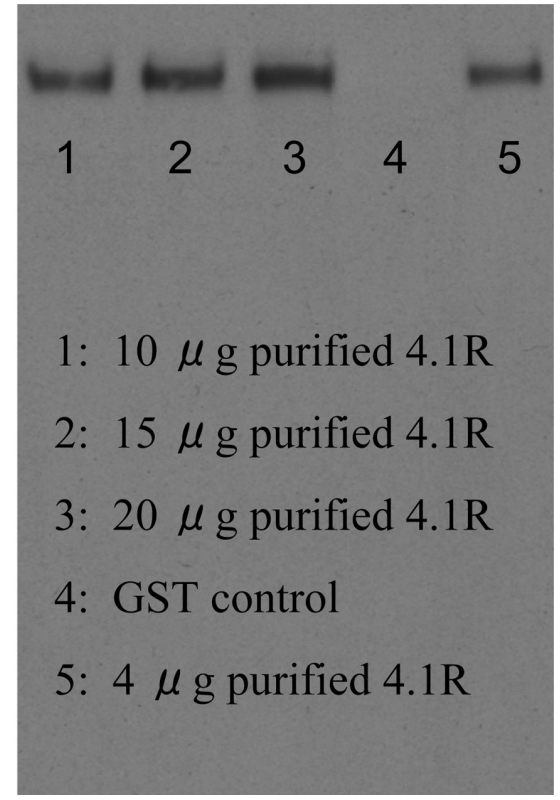

Figure 1. Assessment and validation of human 4.1R protein. (A) Coomassie blue-staining SDS-PAGE gel for purified 4.1R protein from human erythrocytes. (B) Western blot analysis of purified 4.1R protein.

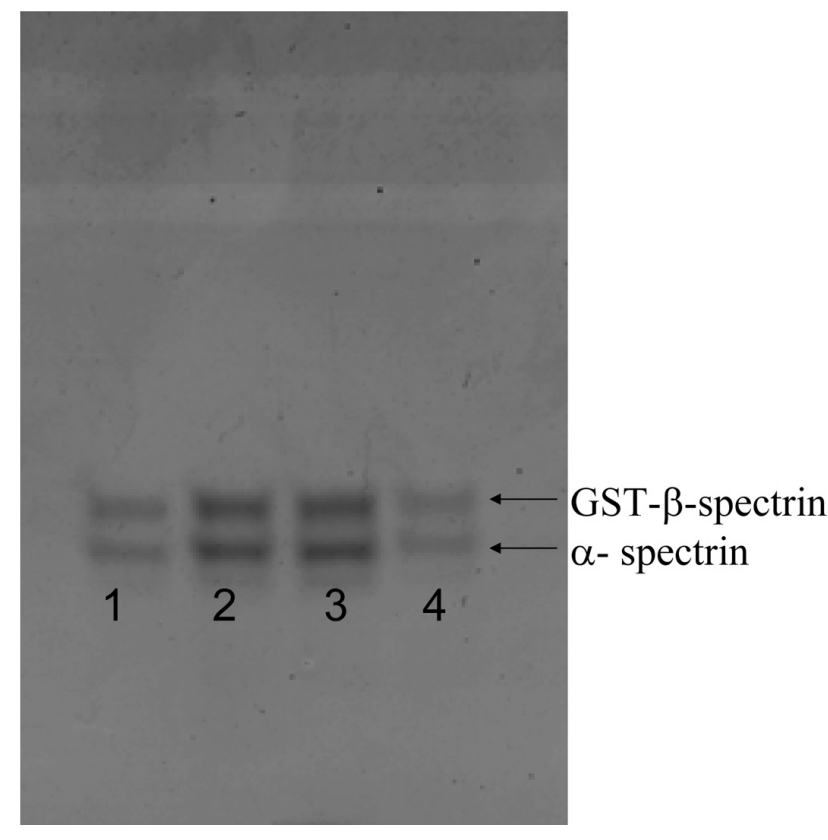

Figure 2. Coomassie blue-staining SDS-PAGE gel for recombinant GST- $\beta$ spectrin and $\alpha$-spectrin. Lanes 1-4 show different fractions of chromatographic collection through the Sephacryl S-200 column.

proteins were then chromatographed through the Sephacryl S-200 column. Fractions were examined by SDS-PAGE, and those with equal amount of $\alpha$ - and $\beta$-spectrins were pooled together for the following binding and GST pull-down assays.

4.1R-spectrin binding assay. $20 \mu \mathrm{g}$ of $\alpha$-spectrin/ GST- $\beta$-spectrin heterodimers were combined with increasing amounts of isotopically $\left({ }^{125} \mathrm{I}\right)$ labeled $4.1 \mathrm{R}$ in a final volume of $200 \mu \mathrm{l}$. The experiments were carried out according to a previously described procedure (7). The bound complex with
${ }^{125}$ I-labeled 4.1R was retrieved using the GSH beads. Finally, the samples were counted using a $\beta$ counter. The binding constants were analyzed and developed by non-linear regression using SPSS software.

GST pull-down assay. Similar to the 4.1R-spectrin binding assay described above, but with no isotopic labeling, the binding complex of $4.1 \mathrm{R}-\alpha$-spectrin/GST- $\beta$-spectrin heterodimers was pulled down using the GSH beads. The bound proteins were then determined by Western blot analysis using the anti-human 4.1R antibody.

Western blot analysis. Western blot analysis for the human 4.1R protein was performed according to a previously described procedure (8-10).

\section{Results and Discussion}

To obtain native 4.1R protein in the binding assessment, 4.1R protein was extracted and purified from human RBCs. As shown in Fig. 1A, a high quality of 4.1R protein was obtained with a molecular weight of $\sim 80 \mathrm{kDa}$; the purity was $>95 \%$ as evaluated by Image $\mathbf{J}$ software according to a previous method (11). The identity of the purified 4.1R protein was then validated by Western blot analysis using an antibody again human 4.1R. The results of Western blotting showed a specific band indicative of 4.1R (Fig. 1B). To gain heterodimers of $\alpha$ - $/ \beta$-spectrins, both $\alpha$ - and $\beta$-spectrins were expressed in the E. Coli system. As indicated by Coomassie blue-staining SDS-PAGE gel (Fig. 2), both recombinant proteins had good production. The fractions with an equal amount of $\alpha$ - and $\beta$-spectrins (corresponding to Lanes 1-4, Fig. 2) were pooled together for the following binding and GST pull-down assays.

The binding experiments were performed by combining $700 \mathrm{nM}$ minispectrin heterodimers with increasing concentrations of ${ }^{125}$ I-labeled full-length native $4.1 \mathrm{R}$ proteins. The 


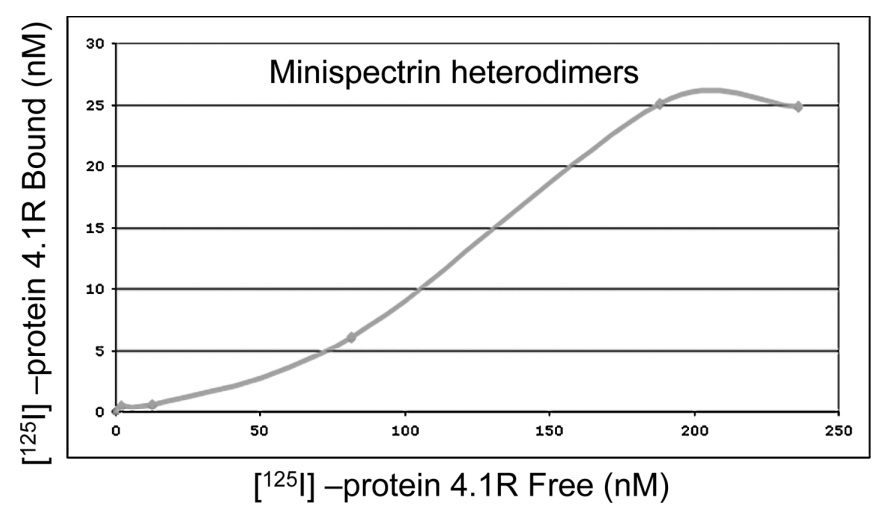

Figure 3. Protein 4.1R binds to the minispectrin heterodimers. Minispectrin heterodimers $(700 \mathrm{nM})$ were mixed with increasing volumes of ${ }^{125}$ I-labeled full-length native $4.1 \mathrm{R}$ proteins. The incubation was conducted at RT for $24 \mathrm{~h}$, and the bound $4.1 \mathrm{R}$ proteins were assayed by a $\beta$ counter.

\section{$\begin{array}{lllllllllll}1 & 2 & 3 & 4 & 5 & 6 & 7 & 8 & 9 & 10 & 11\end{array}$}

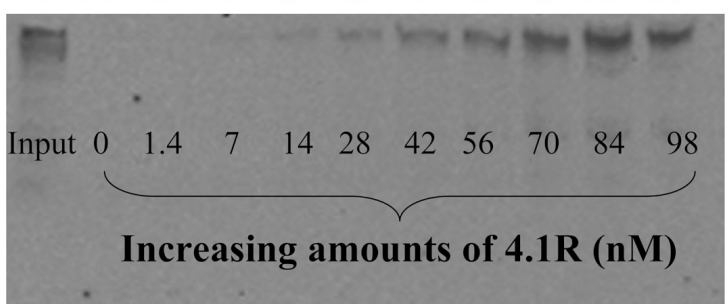

Figure 4. The GST pull-down experiments. Minispectrin heterodimers $(14 \mathrm{nM})$ were mixed with increasing amounts of full-length native $4.1 \mathrm{R}$ proteins. The incubation was conducted at RT for $24 \mathrm{~h}$, and the bound $4.1 \mathrm{R}$ proteins with the minispectrin heterodimers were retrieved by GSH beads. The amount of 4.1R proteins on the beads was reflected by the Western blot analysis using the antibody against $4.1 R$.

incubation occurred at room temperature (RT) for $24 \mathrm{~h}$, and the bound 4.1R proteins were then retrieved and assayed by a $\beta$ counter. As shown in Fig. 3, binding between the minispectrin and 4.1R significantly increased along with the increase in $4.1 \mathrm{R}$ concentration; however, the binding was saturated when the concentration of 4.1R was $>3,150 \mathrm{nM}$. At this point, the ratio of $4.1 \mathrm{R}$ to minispectrin heterodimers was around 4.5. To confirm this result, the GST pull-down experiments were performed by mixing $14 \mathrm{nM}$ minispectrin heterodimers (the $\beta$-spectrin with the GST tag) with increasing amounts of full-length native $4.1 \mathrm{R}$ proteins without ${ }^{125}$ I-labeling. The incubation was conducted at RT for $24 \mathrm{~h}$, and the bound 4.1R proteins with the minispectrin heterodimers (the $\beta$-spectrin with the GST tag) were retrieved on GSH beads and then evaluated by Western blotting. Similar to the binding assay described above, robust binding between 4.1R and minispectrin was observed (Fig. 4). Notably, when the concentration of $4.1 \mathrm{R}$ was $>70 \mathrm{nM}$ (where the ratio of $4.1 \mathrm{R}$ to minispectrin was $>5$ ), the binding of the complex was saturated, consistent with the results from the binding curve (Figs. 3 and 4).

The RBC membrane skeleton is well organized. $\alpha-/ \beta$ spectrins, in the form of head-to-head tetramers, compose a lattice of cytoskeleton, which cross links other structural, linking and integral proteins within the membrane. Thus, spectrins play a central role in establishing the organization of the membrane skeleton $(2,12)$. Mutations in spectrins lead to clinically significant forms of hereditary elliptocytosis and hereditary pyropoikilocytosis (13). Spectrin tetramers associated in a hexagonal array connect the membrane via junctional complexes by interacting with actin filaments, protein $4.1 \mathrm{R}$, and glycophorin $\mathrm{C}$, among which $4.1 \mathrm{R}$ plays a crucial role in regulating the junctional complexes by stabilizing the spectrin-actin network and anchoring it to the membrane (14). Studies with mouse models suggest that deficiency of 4.1R in RBCs results in a considerable reduction in actin filaments and significant loss of cytoskeletal structure and membrane proteins (15-17). Deficiency of 4.1R in human RBCs leads to the pronounced disruption of cytoskeletal meshwork, which is closely associated with anemia and elliptocytosis (18-21). In agreement with previous studies (22-24), the current study presents direct evidence demonstrating the interaction between 4.1R and spectrin heterodimers, suggesting the biological significance of this interaction in maintaining the stability of the plasma membrane skeleton. Additionally, we demonstrated for the first time the binding ratio of 4.1R to spectrin heterodimers, calculated to be 4.5-5. In other words, the binding of spectrin heterodimers by $4.1 \mathrm{R}$ proteins would be saturated when the ratio of $4.1 \mathrm{R}$ to spectrin heterodimers is over 5. Overall, these findings offer a direct demonstration of $4.1 \mathrm{R} /$ spectrin interaction, and provide novel insights into the mechanistic organization of the spectrin filament-centered protein complex.

\section{Acknowledgements}

This work was supported by a grant from the Weihai Science and Technology Development program (no. 2010-3-89-1), and a grant from the State Key Laboratory of Environmental Chemistry and Ecotoxicology (no. KF2010-18).

\section{References}

1. An X and Mohandas N: Disorders of red cell membrane. Br J Haematol 141: 367-375, 2008.

2. Baines AJ: The spectrin-ankyrin-4.1-adducin membrane skeleton: adapting eukaryotic cells to the demands of animal life. Protoplasma 244: 99-131, 2010.

3. Bennett V and Baines AJ: Spectrin and ankyrin-based pathways: metazoan inventions for integrating cells into tissues. Physiol Rev 81: 1353-1392, 2001.

4. Takakuwa Y, Tchernia G, Rossi M, Benabadji M and Mohandas N: Restoration of normal membrane stability to unstable protein 4.1-deficient erythrocyte membranes by incorporation of purified protein 4.1. J Clin Invest 78: 80-85, 1986.

5. Dotimas E, Speicher DW, Guptaroy B and Cohen CM: Structural domain mapping and phosphorylation of human erythrocyte pallidin (band 4.2). Biochim Biophys Acta 1148: 19-29, 1993.

6. Korsgren $\mathrm{C}$ and Lux SE: The carboxyterminal EF domain of erythroid alpha-spectrin is necessary for optimal spectrin-actin binding. Blood 116: 2600-2607, 2010.

7. Korsgren C, Peters LL and Lux SE: Protein 4.2 binds to the carboxyl-terminal EF-hands of erythroid alpha-spectrin in a calcium- and calmodulin-dependent manner. J Biol Chem 285: 4757-4770, 2010

8. Kontrogianni-Konstantopoulos A, Frye CS, Benz EJ Jr and Huang SC: The prototypical 4.1R-10-kDa domain and the 4.1g10-kDa paralog mediate fodrin-actin complex formation. J Biol Chem 276: 20679-20687, 2001.

9. Liu S, Li S and Du Y: Polychlorinated biphenyls (PCBs) enhance metastatic properties of breast cancer cells by activating Rho-associated kinase (ROCK). PLoS One 5: e11272, 2010.

10. Liu S, Suragani RN, Wang F, Han A, Zhao W, Andrews NC and Chen JJ: The function of heme-regulated eIF2alpha kinase in murine iron homeostasis and macrophage maturation. J Clin Invest 117: 3296-3305, 2007. 
11. Liu S, Goldstein RH, Scepansky EM and Rosenblatt M: Inhibition of rho-associated kinase signaling prevents breast cancer metastasis to human bone. Cancer Res 69: 8742-8751, 2009.

12. Palek J: Hereditary elliptocytosis, spherocytosis and related disorders: consequences of a deficiency or a mutation of membrane skeletal proteins. Blood Rev 1: 147-168, 1987.

13. Zhang Z, Weed SA, Gallagher PG and Morrow JS: Dynamic molecular modeling of pathogenic mutations in the spectrin selfassociation domain. Blood 98: 1645-1653, 2001.

14. Birkenmeier CS and Barker JE: Hereditary haemolytic anaemias: unexpected sequelae of mutations in the genes for erythroid membrane skeletal proteins. J Pathol 204: 450-459, 2004.

15. Shi ZT, Afzal V, Coller B, et al: Protein 4.1R-deficient mice are viable but have erythroid membrane skeleton abnormalities. J Clin Invest 103: 331-340, 1999.

16. Reid ME, Takakuwa Y, Conboy J, Tchernia G and Mohandas N Glycophorin C content of human erythrocyte membrane is regulated by protein 4.1. Blood 75: 2229-2234, 1990.

17. Lorenzo F, Miraglia del Giudice E, Alloisio N, et al: Severe poikilocytosis associated with a de novo alpha 28 Arg $\rightarrow$ Cys mutation in spectrin. Br J Haematol 83: 152-157, 1993.

18. Tchernia G, Mohandas N and Shohet SB: Deficiency of skeletal membrane protein band 4.1 in homozygous hereditary elliptocytosis. Implications for erythrocyte membrane stability. J Clin Invest 68: 454-460, 1981
19. Palek $\mathbf{J}$ and Lux SE: Red cell membrane skeletal defects in hereditary and acquired hemolytic anemias. Semin Hematol 20: 189-224, 1983.

20. Conboy J, Mohandas N, Tchernia G and Kan YW: Molecular basis of hereditary elliptocytosis due to protein 4.1 deficiency. N Engl J Med 315: 680-685, 1986.

21. Yawata A, Kanzaki A, Gilsanz F, Delaunay J and Yawata YA: markedly disrupted skeletal network with abnormally distributed intramembrane particles in complete protein 4.1-deficient red blood cells (allele 4.1 Madrid): implications regarding a critical role of protein 4.1 in maintenance of the integrity of the red blood cell membrane. Blood 90: 2471-2481, 1997.

22. Salomao M, Zhang X, Yang Y, et al: Protein 4.1R-dependent multiprotein complex: new insights into the structural organization of the red blood cell membrane. Proc Natl Acad Sci USA 105: 8026-8031, 2008.

23. An X, Debnath G, Guo X, et al: Identification and functional characterization of protein 4.1R and actin-binding sites in erythrocyte beta spectrin: regulation of the interactions by phosphatidylinositol-4,5-bisphosphate. Biochemistry 44: 10681-10688, 2005.

24. Nunomura W, Parra M, Hebiguchi M, Sawada K, Mohandas N and Takakuwa Y: Marked difference in membrane-proteinbinding properties of the two isoforms of protein 4.1R expressed at early and late stages of erythroid differentiation. Biochem J 417: 141-148, 2009 